[From the Robert Hare Chemcal Iaboratory, University of PenNa.]

\title{
ALUMINIUM HYDROXIDE AS A PROTEIN PRECIPITATING REA- GENT IN THE DETERMINATION OF LACTOSE IN MILK.
}

By Wiltiam H. Welker and Howard L, Marsh.

Received April 14, 1913.

In 1908, experimental observations were made by Marshall and Welker in this laboratory which seemed to show that moist jelly-like aluminium hydroxide prepared under certain conditions was a general reagent for the precipitation of colloids from their solutions. A year later we undertook experiments to determin whether this reagent could be used to replace copper sulfate and alkali to remove protein in the determination of lactose in milk. At that time we studied three samples of cow's milk from three different cows and two samples of human milk from two different women; and recently we have analyzed four samples of cow's milk from four different cows and two samples of human milk from two different women.

Experimental Methods. - The milk was brought to room temperature, thoroughly mixed to obtain a uniform sample, and then placed in a small Erlenmeyer flask into the neck of which a $5 \mathrm{cc}$. pipet had been ground. The flask, milk and pipet were then weighed and a $25 \mathrm{cc}$. sample, in the case of cow's milk, or a 15 cc. sample in the case of human milk, was transferred to a $500 \mathrm{cc}$. graduated flask. The Erlenmeyer flask with the remaining portion of the milk and the pipet was again weighed. The difference in weight represented the weight of the milk which had been transferred to the graduated flask.

The removal of the proteins was accomplished by the copper-alkali method. ${ }^{1}$ The reduction of the cupric oxide by the lactose was carried out with Fehling's solution, ${ }^{2}$ and the copper was determined by the cuprous iodide method with the Low modification. ${ }^{3}$ The Soxhlet-Wein tables ${ }^{4}$ were used for the conversion of the copper into terms of lactose.

In the aluminium-hydroxide method a thin jelly was prepared according to Marshall and Welker $^{5}$ by precipitating aluminium hydroxide from a $5 \%$ solution of ammonium alum with ammonium hydroxide and washing by decantation till pure. The aluminium hydroxide was finally centrifuged and the thick jelly obtained was made slightly thinner by agitating it with a few cubic centimeters of water. Two hundred cubic centimeters or less of this thin jelly were added directly to the weighed out sample in the volumetric flask. The flask was shaken vigorously for a few seconds

1 U. S. Dept. Agric., Bureau of Chem., Bull. 107 (revised), p. IIg.

Ibid., p. 48.

Sutton, Volum. Anal., 8th ed., pp. 201-3.

- U. S. Dept. Agric., Bureau of Chem., Bull. ro7 (revised), p. 48.

- Thrs Journal, preceding article. 
to cause intimate mixture of the milk and reagent. The contents of the flask were then diluted to the $500 \mathrm{cc}$. mark, mixed by shaking and filtered through a dry filter. Ioo cc. of this filtrate with $50 \mathrm{cc}$. Fehling's solution were used for each determination. The following figures are the results secured:

\begin{tabular}{|c|c|c|c|}
\hline \multicolumn{4}{|c|}{ SERIES I. } \\
\hline Source. & Saraple. & $\begin{array}{l}\text { Percentage lactose (re- } \\
\text { moving the protein by } \\
\text { copper-alkali method). }\end{array}$ & $\begin{array}{l}\text { Percentage lac- } \\
\text { tose (removing the } \\
\left.\text { protein with } \mathrm{Al}(\mathrm{OH})_{3}\right)\end{array}$ \\
\hline Cow & I & $4 \cdot 57$ & $4 \cdot 52$ \\
\hline Cow & 2 & $4 \cdot 73$ & $4 \cdot 78$ \\
\hline Cow & 3 & $4 \cdot 54$ & 4.66 \\
\hline Human & 4 & 6.59 & 6.44 \\
\hline Human & 5 & 6.09 & 6.10 \\
\hline \multicolumn{4}{|c|}{ SERIES II. } \\
\hline Cow & 6 & 4.64 & 4.69 \\
\hline Cow & 7 & $4 \cdot 7 \mathrm{I}$ & $4 \cdot 74$ \\
\hline Cow & 8 & $4 \cdot 7 \mathrm{I}$ & $4 \cdot 71$ \\
\hline Cow & 9 & $4 \cdot 79$ & $4 \cdot 79$ \\
\hline Human & IO & 6.28 & 6.29 \\
\hline Human & I I & 7.02 & 7.02 \\
\hline
\end{tabular}

These results are in all cases the averages of very closely agreeing duplicate determinations. On the basis of our results, we believe that aluminium hydroxide can be used to advantage in the removal of protein, in the determination of lactose in milk. The use of an excess of aluminium hydroxide does not influence the final results and the filtration is more rapid than in the copper-alkali method, thus enabling one to complete a determination in considerably less time than by the latter method.

\section{CHEMILUMINESCENT REACTIONS WITH PHYSIOLOGIC SUB- STANCES.}

BY F. ALEX MCDERMOTT.

Received April 10, 1913.

In the fall of $19 \mathrm{I} 2$, the writer's attention was called ${ }^{1}$ to the fact that if a lump of potassium cyanide be dropped into urin, a faint light will be observed if the vessel be taken into a dark room after a few minutes and shaken so as to mix the strata formed. In a series of tests with this phenomenon, the writer has been able to observe only a very faint light when using a $99 \% \mathrm{KCN}$, but it was found that if to the solution of cyanide in urin, a strong, alkaline solution of hydrogen peroxide be added, a considerably brighter emission of light would occur. Subsequent experiments showed that potassium formate or formaldehyde could be used in place of the cyanide, with equally good results. As yet it is not known just what constituent of urin is responsible for the reaction; urin ap-

${ }^{1}$ By Dr. Otto Meyer, of Richmond, Va. 